\title{
Myocardial transcription factors in diastolic dysfunction: clues for model systems and disease
}

\author{
Alexander T. Mikhailov ${ }^{1}$, Mario Torrado ${ }^{1}$ \\ ${ }^{1}$ Institute of Health Sciences University of La Coruña, La Coruña, Spain
}

\begin{abstract}
There are multiple intrinsic mechanisms for diastolic dysfunction ranging from molecular to structural derangements in ventricular myocardium. The molecular mechanisms regulating the progression from normal diastolic function to severe dysfunction still remain poorly understood. Recent studies suggest a potentially important role of core cardio-enriched transcription factors (TFs) in the control of cardiac diastolic function in health and disease through their ability to regulate the expression of target genes involved in the process of adaptive and maladaptive cardiac remodeling. The current relevant findings on the role of a variety of such TFs (TBX5, GATA-4/6, SRF, MYOCD, NRF2, and PITX2) in cardiac diastolic dysfunction and failure are updated, emphasizing their potential as promising targets for novel treatment strategies. In turn, the new animal models described here will be key tools in determining the underlying molecular mechanisms of disease. Since diastolic dysfunction is regulated by various TFs, which are also involved in cross talk with each other, there is a need for more in-depth research from a biomedical perspective in order to establish efficient therapeutic strategies.
\end{abstract}

Keywords

Diastolic dysfunction; Transcription factors; MicroRNAs 


\section{Introduction}

Heart failure with preserved ejection fraction (HFpEF), termed in the past "diastolic HF," is a heterogeneous clinical syndrome of impaired diastolic function with normal or near normal left ventricular EF (LVEF $\geq 50 \%$ ). Patients with HFpEF have a normal-sized LV, often with signs of a mild hypertrophy, with impaired filling, to different degrees, due to abnormal LV relaxation and increased LV stiffness. While extra-cardiac pathophysiological conditions, such as hypertension, obesity, diabetes mellitus, renal dysfunction, and aging, can contribute to HFpEF development, a maladaptive concentric LV remodeling appears to be the main underlying substrate of impaired diastolic function in patients (recently reviewed in [1-7]).

Studies of gene expression in human HFpEF settings are limited by the low availability of tissue samples from diseased and non-failing control hearts. These limitations with human cardiac tissue are overcome, with varying degrees of success, by the use of patient-mimicking animal models $[8,9]$ in which HFpEF is developed as a consequence of spontaneous and experimentally induced hypertension or metabolic syndromes (obesity and diabetes). The results of these and other cross-sectional studies showed that LV diastolic dysfunction conditions can be associated with: (1) fluctuation in cardiac calcium-handling protein levels [10], (2) alterations in proteins, which play an important role in maintaining the sarcomeric structure and functionality [11-13], and (3) aberrant extracellular matrix protein turnover [14-17]. Although these data reflect some underlying expression features in HFpEF settings, the molecular mechanisms regulating the progression from normal diastolic function to severe dysfunction and then to HFpEF still remain poorly understood. Only a few recent studies point to the cardiomyocyte circadian clock [18] and mineralocorticoid receptor signaling [19] as potentially important mediators in triggering and in the progression of diastolic dysfunction in mice.

Transcription factors (TFs) are essential players in the control of gene expression by influencing RNA polymerase activity in a gene-selective manner. One distinct feature of TFs is that they have DNA-binding domains which recognize specific sequences in the promoters or enhancers of target genes. The other characteristic feature of their structure is an activation/repression domain that interacts with various cofactors, which either promote or impair the transactivation of target genes. Normal heart development is orchestrated by a suite of highly conserved TFs that includes (among others) TBX5, GATA-4, GATA-6, SRF/MYOCD, NRF2, and PITX2 (Fig. 1a). These multifaceted cardio-enriched TFs are responsible for the tight regulation of expression of a broad array of myocardial-related genes during heart development, and the perturbation of expression and regulation of these TFs disrupts normal heart structure and function (recently reviewed in [20,21]). Of note, these core TFs can physically interact with each other and co-occupy the promoters of target genes (Fig. 1b). These TFs are co-expressed in the adult human myocardium (Fig. 1c), suggesting that interactions between them could be physiologically relevant in heart.

It has become increasingly apparent that fetal cardiac-enriched TFs play critical roles in the regulation of expression of many myocardial genes in the adult normal and diseased heart (reviewed in [22-24]). Regarding heart disease, there is recent, mounting evidence suggesting a causal and specific role of several cardiac-enriched TFs in development and progression of HFpEF. In this review, we provide a research status update of the expression and function of the fetal cardiac TFs in adult diastolic dysfunction. Targeting TFs could be a promising therapeutic approach to modulate gene expression in the HFpEF in a specific fashion. Although TFs have traditionally been considered as "undruggable" targets for therapeutics, targeting them, due to recent technological advances, is again becoming a realistic therapeutic perspective (recently reviewed in [25]). 
A

TBX5

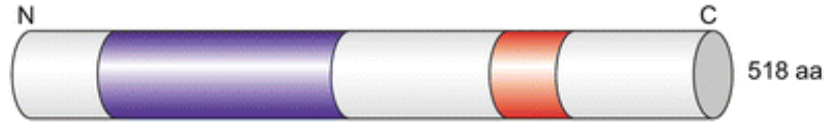

\section{GATA-4}

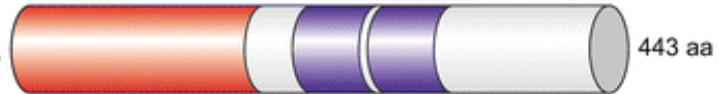

GATA-6

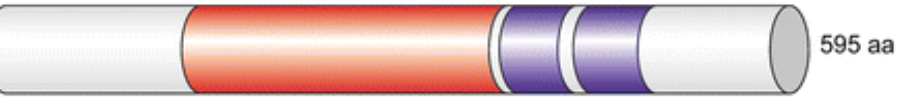

SRF
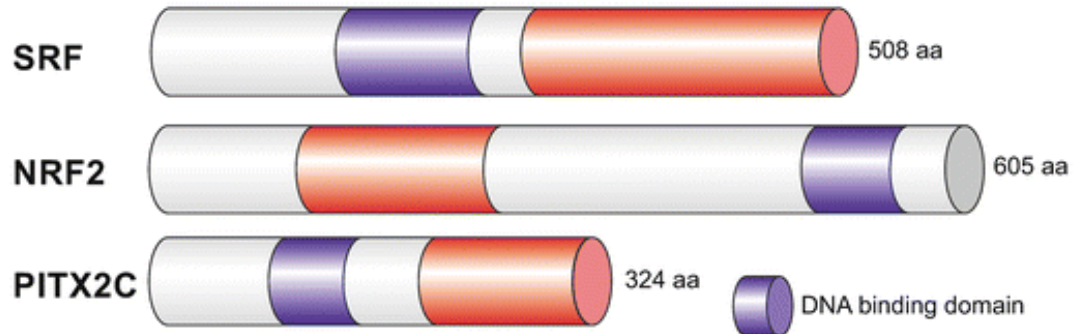

DNA binding domain

Transactivation domain

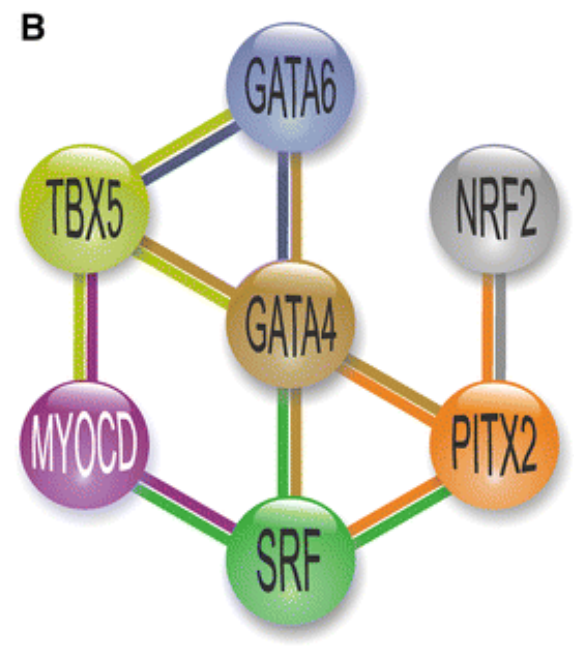

C

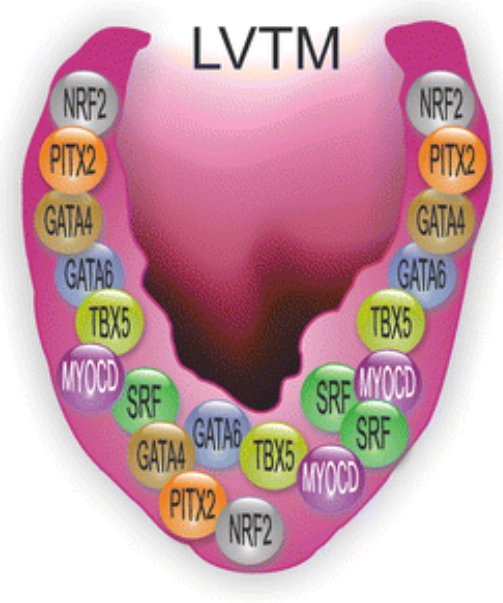

Fig. 1. Schematic overview of cardiac-enriched transcription factors governing diastolic function. a DNA-binding and transactivation domains of the human TBX5, GATA-4, GATA-6, SRF, NRF2, and PITX2 transcription factors (TFs) are shown [129]. N/C: amino/carboxyl terminus; aa-amino acids. b Combinatorial TF interactions. Schematic illustrates TBX5::GATA4 [130], TBX5::GATA-6 [131], TBX5::MYOCD [132], GATA-4::GATA-6 [54], SRF::MYOCD [68], SRF::PITX2 [133], PIXT2::GATA-4 [134], and PITX2::NRF2 [82] protein-protein interactions that lead to cooperative regulation of target gene expression in vitro. cTBX5 [29], GATA-4 [135], SRF [136], MYOCD [137], NRF2 [138], and PITX2 [97] are co-expressed in the adult human left ventricle (LV), suggesting that the interplay of these TFs in vitro (shown in b) also takes place in vivo (data for GATA-6 equivalent to those for GATA-4 are currently lacking). LVTF-left ventricular TF machinery which can be involved in molecular regulation of diastolic function 


\section{TBX5 transcription factor}

The TBX5 gene belongs to a family of genes that share the so-called T-box DNA-binding domain of about 180 amino acid residues (reviewed in [26-28]). TBX5 is expressed in human embryonic and adult heart [29] and transcriptionally activates multiple cardiomyocyte lineageassociated genes encoding, among others, NPPA (natriuretic peptide precursor A or ANP), CX40 (connexin 40), MYH7 (myosin, heavy chain 7, cardiac muscle, beta), TNNI2 (troponin I type 2 skeletal), TNNT2 (troponin T type 2 cardiac), and SCN5A (sodium channel, voltage-gated, type V alpha subunit) [30, 31]. It should be noted that several splicing variants of TBX5 mRNA have been identified in the adult mouse [32] and human heart [33], and the resulting protein isoforms are characterized by diverse transcriptional and functional activities. This production of different $T B X 5$ isoforms seems to be a mechanism which can play an important role in TBX5 dosage regulation.

TBX5 function in the heart appears to be exquisitely sensitive to gene dosage. Both over- and under-expression of the $T B X 5$ gene have equally deleterious effects on the heart. In transgenic mouse embryos, cardiac TBX5 overexpression results in inhibition of ventricular-specific gene expression and impaired ventricular trabeculation [34]. Similarly, in humans, TBX5 overexpression due to gene duplication leads to cardiac abnormalities [35]. In the mouse, systemic $T B X 5$ gene ablation $\left(T B X 5^{-/}\right.$mice) causes decreased expression of myocardial genes associated with extreme underdevelopment of the heart, whereas heterozygous $T B X 5^{-1+}$ mice mimic heart and limb abnormalities observed in Holt-Oram ("heart-hand") syndrome (HOS) in humans [36]. Of note, TBX5 was the first T-box gene where loss-of-function mutations (mainly located within the highly conserved T-box domain) were found to cause a HOS (recently reviewed in [37]); diastolic dysfunction is detected in a cohort of HOS patients [38]. Patients with low diastolic blood pressure show substantially increased ventricular-arterial stiffness and a tendency for diastolic dysfunction (reviewed in [39]). In this regard, large-scale genome-wide association studies have identified an association of TBX5 with diastolic blood pressure [40].

Mice with heterozygous conditional deletion of TBX5 (TBX5 $5^{\text {del/ }}$ mice) manifested a clear LV diastolic dysfunction (attributed to a disturbance of LV isovolumic relaxation) with preserved LV systolic function. In addition, a significant correlation was found between decreased TBX5 gene expression and increased LV filling pressure [41]. However, the possibility that deterioration of LV relaxation is secondary to right heart overloads due to atrial or ventricular septal defects in these mice could not be excluded. The latter issue has been addressed by Zhu et al. [38] who generated mice $\left(T B X 5^{\text {Vdel/ }+}\right.$ mice) with haploinsufficiency of $T B X 5$ in only ventricular cardiomyocytes. These mice did not have septal or any other defects in cardiac structure, but did manifest impaired ventricular relaxation and diastolic dysfunction, whereas the systolic function remained normal. In the $\mathrm{LV}$ of $T B X 5^{\text {Vdel/ }}$ mice, the decrease in $T B X 5$ expression was paralleled by a comparable reduction in transcript and protein levels of SERCA2a (sarcoplasmic reticulum $\mathrm{Ca}^{2+}$ ATPase) which was found to be a dose-dependent target of TBX5 in cardiomyocytes. This model suggests that the molecular pathogenesis of isolated diastolic dysfunction is due to downregulation of the TBX5-SERCA2a pathway in ventricular cardiomyocytes that may have implications for clinical management. Intriguingly, in this regard, a significant downregulation of cardiac SERCA2 $a$ levels has been observed in the diabetic (mRen-2)27 rat model of HFpEF [10].

\section{GATA-4 and GATA-6 transcription factors}

GATA-binding protein 4 (GATA-4) and GATA-binding protein 6 (GATA-6) are the members of the GATA family of zinc finger transcription factors which recognize the GATA motif in the promoters of most cardiac muscle-specific genes, especially those that are altered by the hypertrophic response (reviewed in [24, 42]). GATA-4 directly regulates expression of MYH6 (myosin, heavy chain 6, cardiac muscle, alpha), MYL1 (myosin, light chain 1, alkali, skeletal, fast), TNNC1 (cardiac troponin C type 1), NPPA (natriuretic peptide precursor A), NPPB (natriuretic peptide precursor B), ANKRD1 (cardiac-restricted ankyrin repeat protein 1), SLC8A1 (solute carrier family 8 sodium/calcium exchanger, member 1), and CDK2 and 4 (cyclin- 
dependent kinase 2 and 4) [42-44]. GATA-6 seems to regulate the expression of NPPA, EDN1 (endothelin-1), AT1A (angiotensin II receptor isoform A), and SEMA3C (semaphorin 3C) [45]. In addition, either GATA-4 or GATA-6 is essential for expression of other cardio-associated TFs that regulate the onset of cardiomyocyte gene expression in early cardiogenesis. Not surprisingly, when both GATA-4 and GATA-6 were simultaneously disrupted in mouse embryos, the onset of cardiac development was completely blocked [46].

GATA-4 and GATA-6 are expressed in both fetal and adult cardiomyocytes and required for physiological hypertrophic remodeling during postnatal heart growth as suggested by controlled GATA-4 [47] and GATA-6 overexpression [48, 49] in the heart. There is a good reverse correlation between these results and the data from conditional GATA-4-/GATA-6-knockout models: Mutant mice with mid-to-late fetal cardio-specific deletion of GATA-4 [50] or combined deletion of GATA-4 and GATA-6 [49] develop dilated cardiomyopathy with severe systolic dysfunction in adulthood. Similarly, the simultaneous loss of both GATA-4 and GATA-6 in perinatal cardiomyocytes causes progressive systolic dysfunction and ventricular dilatation [51].

GATA-4 and GATA-6 regulate cardiac morphogenesis, cardiomyocyte differentiation, and gene expression in a dosage-dependent manner. Mice homozygous for a hypomorphic GATA-4 mutation $\left(G A T A-4^{H / H}\right.$ mice), expressing $70 \%$ less GATA-4 protein in the atria and LV, displayed a common atrioventricular canal, double outlet right ventricle, and hypoplasia of the LV compact myocardium. Altered diastolic function was suspected in mutants because ventricular active relaxation was found to be correlated with the compact myocardium development in normal mouse embryos [52]. In fact, in vivo hemodynamics in $G A T A-4^{H / H}$ mice did reveal signs of severe diastolic dysfunction, in the absence of changes in systolic function. The diastolic dysfunction phenotype of these mutants did not result from downregulation of putative GATA-4 target genes in the heart; GATA-6 expression was not altered in GATA-4 $4^{H / H}$ mutant embryos [53]. This fetal heart model was suggestive of a possible involvement of GATA-4 in the regulation of diastolic function of fetal heart. However, the possibility of a direct causative role for GATA-4 in regulating the diastolic function remained in question, since mutant mice lacking $70 \%$ of the GATA-4 protein displayed complex cardiac structural and functional abnormalities.

Recently, the functions of GATA-4 and GATA-6 in adult heart have been highlighted using mouse models of temporally controlled, cardiomyocyte-specific gene inactivation [51]. In the adult heart, simultaneous cardiomyocyte-specific deletion of GATA-4 and GATA-6 leads to dramatically attenuated diastolic function, whereas systolic performance is only slightly impaired. Molecular characterization of these mutant mice demonstrated that expression of the GATA-4 preferential target, MYH6 (myosin, heavy chain 6, cardiac muscle, alpha), is decreased in the diastolic heart. However, the expression of the other GATA-4-dependent gene, MYH7 (myosin, heavy chain 7, cardiac muscle, beta) as well as the NPPA gene (a bona fide target for both GATA-4 y GATA-6 factors [54]) is increased in mutant myocardium, suggesting that the diastolic phenotype could not result from a general downregulation of GATA-4/6 target genes.

Overall, therefore, the results of GATA-4 and GATA- 6 knockdown in the adult heart strongly suggest that stress-induced downregulation of these TFs in myocardium might play a critical role in or contribute to the development of diastolic dysfunction. It should be noted in this sense that either GATA-4 or GATA-6 physically interact with FOG-2 (friend of GATA-2), a multi-zinc finger transcription cofactor, which is co-expressed with $G A T A-4 / 6$ in the heart and is known to potently repress GATA-4 activation of target promoters (reviewed in [55]). Adult mice with fetal cardiomyocyte-restricted loss of FOG-2 developed a dilated cardiac phenotype, indicating that FOG-2 is required for normal adult heart function [56]. FOG-2 upregulation is a feature of human cardiomyopathic heart. Mice with cardiac-specific overexpression of FOG-2 display normal-sized ventricles with enlarged atria; a significant downregulation of MYH6 and SERCA2 $a$ was found in ventricular myocardium of FOG-2 transgenic mice [57]. Although unproven as yet, it is tempting to speculate that a severe decrease in GATA-4 and GATA-6 transcriptional activity, which could lead to diastolic dysfunction [51], might be associated, at least in part, with overexpression of FOG-2 in the stressed heart. 


\section{SRF and myocardin transcriptional regulators}

Serum response factor (SRF) is a founding member of the MADS (MCM1, agamous, deficiens, and SRF)-box superfamily of TFs. This ubiquitously expressed TF binds DNA as a dimer (through the highly conserved DNA-binding and dimerization MADS-box domain) and regulates many target genes through serum response elements in their promoters (reviewed in [58, 59]). More than 200 SRF-dependent genes that are important for metabolism, cytoskeleton, extracellular matrix, ion transport, stress response, transcription, and translational regulation have been identified in the ventricular myocardium [24, 60]. Alternative splicing generates several isoforms of SRF, with full-length SRF being the predominant cardiac isoform. SRF is highly expressed in the heart during embryonic, fetal, and postnatal development. Gene-targeting studies in mouse models provided insights into potentially pathological consequences of both $S R F$ redundancy and deficiency in the adult heart. Augmented $S R F$ expression leads to hypertrophic cardiomyopathy, while inhibition of SRF activity results in development of dilated cardiomyopathy (reviewed in [61, 62]).

During aging, the heart undergoes, even in the absence of evident cardiovascular pathology, subtle remodeling changes that include moderate LV hypertrophy and altered LV diastolic function. $S R F$ expression is increased from adulthood to senescence. In this context, in transgenic mouse models, in which upregulation of the $S R F$ gene was low-to-mild, young adult animals displayed accelerated cardiac aging and developed diastolic dysfunction [63]. A subsequent report showed that a low-forced $S R F$ expression did not affect either cardiac gene expression or cellular structure [64]. Whether low-amplitude increases in cardiac $S R F$ levels are causative for triggering diastolic dysfunction or merely reflective of aging heart remodeling remained unclear.

$S R F$ is characterized by a relatively low intrinsic transcriptional activity itself, but its association with a wide array of cofactors that possess potent transactivation domains leads to a strong enhancement of $S R F$ transactivation capacity in a cell context-dependent manner. One of such cofactors is myocardin (MYOCD) that regulates the expression of multiple smooth muscle (SM) and cardiac contractile genes, including CNN1 (calponin 1, basic, smooth muscle), MYH11 (myosin, heavy chain 11, smooth muscle), ACTA2 (actin, alpha 2, smooth muscle, aorta), ACTG2 (actin, gamma 2, smooth muscle), TAGLN (transgelin), and MYH6 (myosin, heavy chain 6, cardiac muscle, alpha) (reviewed in [23, 65-68]).

Loss- and gain-of-function experiments demonstrated that $M Y O C D$ is absolutely required for maintenance of adult heart function. Postnatal cardio-restricted MYOCD knockdown induces dilated cardiomyopathy and fatal HF in mice [69], while forced expression of MYOCD in ventricular myocardium impairs LV systolic function and cardiac ECG activity in pigs [70]. In light of these results, it comes as no surprise that a strong association between the altered expression of $M Y O C D$ and cardiac pathological conditions has been established in different animal models as well as patients with end-stage HF (reviewed in [23, 67, 68]).

In the porcine model of doxorubicin (Dox)-induced HFpEF, gene expression profiling revealed a significant upregulation of $M Y O C D$ - and $M Y O C D$-dependent SM genes in falling $\mathrm{LV}$ myocardium, with the $S R F$ levels unchanged as compared to controls. ACTG2 was the most remarkably upregulated $M Y O C D$ target gene in Dox-injected piglets. Of note, the ectopic expression of $A C T G 2$ in the mouse heart significantly reduces the rates of ventricular relaxation [71]. In vivo silencing of endogenous upregulated $M Y O C D$ via intramyocardial delivery of shorthairpin RNAs at mid-advanced stages of $\mathrm{HFpEF}$ resulted in downregulation of $M Y O C D$ dependent SM gene expression in the failing porcine myocardium. Such adjusting of MYOCD and SM-target expression levels to the range of physiological variation led to restoring diastolic function and extending the survival of failing animals without compromising the physiological functions of $M Y O C D$ signaling as part of the adaptive response of the heart to stress [72]. These findings demonstrate that the normalization of altered MYOCD signaling could represent a strategic operative tool for the prevention of the development of diastolic dysfunction. 


\section{NRF2 transcription factor}

Nuclear factor erythroid 2-related factor 2 (NRF2) is a redox-sensitive basic leucine zipper TF which controls the gene expression of several hundred of detoxification and antioxidant enzymes bearing a target sequence, known as the antioxidant-responsive element (ARE), in their promoters [73]. NRF2 transcriptionally activates ARE-bearing genes in response to oxidative stress-induced injury (reviewed in $[74,75])$. NRF2 ubiquitously expressed in the cardiovascular system is an essential endogenous suppressor of oxidative stress in both cardiomyocytes and cardiac fibroblasts, and NRF2 deficiency appears to be a condition for the early onset of HF in humans $[76,77]$. In addition, functional NRF2 polymorphisms are associated with risk of human cardiovascular disorders [78].

The results from loss- and gain-of-function experiments in animal models have provided clues to the understanding of the role/impact of $N R F 2$ in cardiac function. Several lines of mice devoid of NRF2 have been generated by homologous recombination in embryonic stem cells, using various strategies. In all cases, disruption of the targeted $N R F 2$ gene did not lead to any apparent structural and functional abnormalities in the neonatal and early postnatal heart under non-stressed physiological conditions [79]. However, NRF2 deficiency resulted in a rapid onset of cardiac dysfunction during experimental pressure overload (due to transverse aortic constriction [80]) or regional ischemic injury (due to cardiac artery occlusion [81, 82] in young adult (2-month-old) mice. These results indicated that NRF2 inhibition can increase sensitivity of the young heart to pathological stress and thus exaggerate susceptibility to cardiac dysfunction. Recently, it was found that NRF2 loss-of-function leads to suppression and distortion of regenerative processes in the apex resection mouse model [82].

Further studies focused on adult NRF2-knockout mice (5-6 months of age) demonstrated that a $N R F 2$ gene deficiency leads to the development of LV diastolic dysfunction even in non-stressed heart. Impaired diastolic function in these NRF2 knockouts was associated with mild cardiac hypertrophy but preserved systolic function. In addition, a significant decline in cardiac SERCA2a and total glutathione levels were found in the myocardium of these animals [83]. The results suggest that $N R F 2$ is an essential regulator of cardiac diastolic function upon non-stressed physiological conditions and that its downregulation might cause severe maladaptive reactions.

$N R F 2$ expression is upregulated during early stages of physiological cardiac hypertrophy but decreased at mild pathological hypertrophy (a condition often associated with HFpEF development). In various models of hypertrophic cardiomyopathy, forced expression of $N R F 2$ and its target genes, such as $H O-1$ (heme oxygenase-1), GPX (glutathione peroxidise), TXNRDI (thioredoxin reductase 1), NQO1 (NADPH:oxioreductase 1), and SOD2 (superoxide dismutase 2, mitochondrial), significantly reverses LV remodeling and fibrosis [84, 85]. Similarly, an increase in $N R F 2$ expression/activity (due to phytochemical intake) attenuates diastolic dysfunction in hypertensive Dahl salt-sensitive rats with HFpEF [86].

In patients, diabetic cardiomyopathy is characterized by signs of clinically significant diastolic dysfunction independent of coronary disease or hypertension [87]. Expression of NRF2 is downregulated in cardiomyocyte nuclei in cardiac samples from patients with diabetes. Promisingly, emerging evidence revealed that induction of $N R F 2$ expression can protect from diabetes-associated cardiac dysfunction by decreasing the oxidative stress and preventing oxidative DNA damage of myocardium (reviewed in [88, 89]). 


\section{PITX2 transcription factor}

The PITX2, a paired-like homeodomain transcription factor 2, was originally identified as the candidate gene for the human Axenfeld-Rieger syndrome [90] associated, although not frequently, with congenital heart defects [91, 92]. Aggregating evidence demonstrates that PITX2 is expressed, as three distinct variants/isoforms (A, B, and C), in the mammalian and human heart, with PITX2C being the predominant or the only variant detected in the adult LV myocardium [9398]. A fourth isoform, PITX2D described, to date, only in humans acts as a dominant-negative factor [99]. PITX2 regulates the expression of cyclin D2 (CCND2) [100], forkhead box J1 (FOXJ1) TF [101], lymphoid enhancer factor (LEF-1) [102], natriuretic peptide precursor A (NPPA) [103, 104], myogenic factor 5 (MYF5) [105], and antioxidant scavenger genes [82]. Other target genes of PITX2 include channel and calcium-handling genes, and genes are expressed in intercalated disks of cardiac myocytes (recently reviewed in [106]).

Selective PITX2 deletion in the developing myocardium resulted in delayed differentiation of ventricular (but not atrial) cardiomyocytes and enlargement of right heart chambers associated with severely impaired ventricular systolic function [107]. The roles played by PITX2 within the four chambered adult heart are still poorly understood. Genes involved in cell junction assembly, ion transport, and proliferation pathways were found to be activated in mouse mutants with conditionally inactivated PITX2 in the postnatal atrial myocardium [108], but it is unclear whether these are direct or indirect PIXT2C target genes in a cardiomyocyte background. Recently, a total of 505 direct PITX2 target genes were identified in the mouse postnatal ventricular myocardium, including genes encoding transport chain components and reactive oxygen species scavengers [82].

While several lines of evidence from animal models as well as clinical studies strongly support that PITX2C has a role in susceptibility to atrial fibrillation [94, 109-114], the relevance of this TF to LV diastolic dysfunction remained unsuspected and was therefore not tested till recently. LV levels of PITX2C mRNA and protein were first shown to be elevated in the Dox-induced porcine model of HFpEF [97]. In particular, it was found that the expression of PITX2C is significantly reactivated in HFpEF myocardium which, in turn, is associated with increased expression of a restrictive set of PITX2 target genes. Among these, MYF5 (myogenic factor 5) was identified as the top upregulated gene. In vitro, forced expression of PITX2C in cardiomyocytes activates MYF5 in dose-dependent manner. Of note, ectopic overexpression of MYF5 in the heart activates a skeletal muscle gene expression that results in progressive cardiomyopathy $[115,116]$. The latter suggests that aberrant PITX2-MYF5 co-activation seen in the porcine model of HFpEF might negatively impact on diastolic cardiac function.

Expression of both PITX2 and MYF5 was detected in LV myocardium from HFpEF piglets [97] as well as cardiomyocyte-like (CML) cells from patients with dilated cardiomyopathy. Forced expression of SERCA2a improved contractility of CML cells that, in turn, was associated with downregulation of PITX2 and MYF5 in SERCA2a-transduced cardiomyocytes [117]. Myocardial hypertrophy and subsequent diastolic dysfunction are prominent features of diabetic cardiomyopathy. In this sense, PITX2C is significantly upregulated in human cardiac myocytes in response to high glucose treatment [118].

In spite of the results discussed above, it is not known whether upregulation of PITX2C can cause HFpEF or if its activation is merely a secondary manifestation of impaired LV diastolic function. Notably, PITX2 expression is induced in ischemically injured ventricular myocardium and is required for neonatal cardiac regeneration in mice [82]. 


\section{Conclusions and perspectives}

HFpEF can be considered as the new epidemic of the twenty-first century, since the prevalence of this complex clinical syndrome caused by a variety of diseases has remained high or has even increased throughout the last two decades (reviewed in [6]). Investigation into molecular mechanisms underlying HFpEF has been hampered by lack of relevant and tractable models in animals which could recapitulate phenotypic features of diastolic dysfunction in humans. Nevertheless, some studies which focused on single specific endpoints have revealed concordant changes in increased calcium and sodium levels and elevated expression of the stiff titin isoform with myocardial diastolic dysfunction (reviewed in [3]). Despite these efforts, advancement has been made over the past several years, proving essential for the identification of the transcriptional regulation of diastolic function with potential implications for HFpEF. Surprisingly, the study of the molecular regulatory background of diastolic dysfunction and HFpEF does not show a great diversity of responsible TFs and downstream gene pathways (Fig. 2). All of these TFs play important roles in cardiac development and regulate inducible gene expression in cardiac myocytes in the adult heart. It should be pointed out that there is an experimental evidence to suggest that diastolic dysfunction could result from altered expression of more than one of these TFs in the LV myocardium. In the porcine model of HFpEF, upregulation of MYOCD and its SMtarget genes is associated with augmented PITX2 and MYF5 expression, suggesting an additive negative effect on diastolic function [72,97].

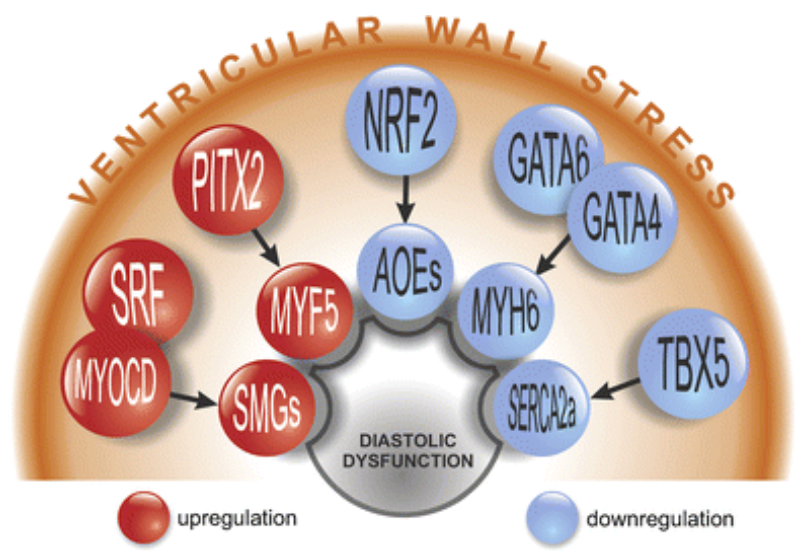

Fig. 2. Dissecting the roles of cardiac TFs in development of diastolic dysfunction. Cardiac transcription factors (TFs) are members of gene regulatory circuits, each of which can play a role in the control of a branch of terminal effector genes in ventricular myocardium. The results from loss- and gain-of-function experiments in animal models provide clues toward the understanding the roles of TBX5, GATA-4/6, SRF/MYOCD, NRF2, and PITX2 in development of cardiac diastolic dysfunction. Severe inhibition of TBX5, GATA-4/6, and NRF2 as well as augmented expression of $S R F / M Y O C D$ and PITX2 leads to molecular changes that may contribute to ventricular diastolic impairment. These changes include, respectively, downregulation of SERCA2a, MYH6, and antioxidative enzyme (AOE) genes, on the one hand, and activation of smooth muscle (SM) and skeletal muscle (MYF5) gene expression in ventricular myocardium, on the other hand. AOE - NRF2 target genes encoding HO-1, GPX, TXNRD1, NQO1 (NAD(P), SOD2, and SOD3. SM-MYOCD target genes encoding CNN1, MYH11, ACTA2, ACTG2, and TAGLN. See text for further details 
The discovery that deficiency in core cardiac TFs, such as TBX5, GATA-4/6 and NRF2, causes diastolic dysfunction will prompt an evaluation or re-evaluation of the expression of these TFs in other animal models of HFpEF as well as patients with diastolic dysfunction. Perhaps, the best example of this is the identification of a TBX5-dependent pathway in the regulation of diastolic function that has direct relevance to patients with HOS [38]. Collectively, the results suggest that mutant mice with cardio-specific knockdown of TBX5, GATA-4/6, or NRF2 are promising models for investigating the molecular mechanisms underpinning the development of diastolic dysfunction.

Through the use of other animal models that mimic of HFpEF, upregulation of SRF, MYOCD, and PITX2 is linked to the development of diastolic dysfunction, whereas restoration of their altered expression to the range of physiological variation can potentially reduce or even eliminate diseases, as demonstrated through silencing MYOCD overexpression in the porcine model of HFpEF [72]. Of note, detection of elevated levels of MYOCD in circulating blood cells has been shown to have a certain biomarker utility in patients (reviewed in [68]). Thus, it appears to be reasonable to test whether adjusting a given TF expression level to the range of its physiological variation may lead to restoring diastolic function in preclinical settings.

In sum, the above studies clearly illustrate how inappropriately high or low expression of a set of cardiac TFs can lead to diastolic dysfunction (see Fig. 2). Therefore, manipulating their levels to either increase the expression of stress-downregulated TFs or suppress the expression of stressupregulated TFs may represent therapeutic tools to ameliorate HFpEF progression. Mechanistically viewed, modulation of TFs in myocardium in vivo can be achieved by direct targeting (through gene therapy) their expression levels as well as by affecting the combinatory TF interactions (see Fig. 1b) or altering their DNA-binding activity (reviewed in [25]). In this context, a number of delivery platforms have been described that are translatable to the clinical setting (reviewed in [119]). However, it is necessary to develop more efficient delivery systems for cardio-selective (not systemic) targeting of TFs in the diastolic heart. An alternative and complementary approach (as demonstrated in the case of NRF2; see [89]) may be pharmacological activation/inhibition of the candidate $\mathrm{TF}$ or its critical cofactors for improving diastolic dysfunction in certain cardiovascular settings.

In addition to the points raised above, it is essential to pinpoint a possible involvement of microRNAs (miRNAs) in pathophysiological mechanisms underlying HFpEF (recently reviewed in [120]). Compared to the cardiac-enriched TFs (cardiac TF-ome system) which control gene expression at the level of transcriptional regulation, cardiac-expressed microRNAs (cardiac miRNA-ome system) regulate gene expression at posttranscriptional levels. Rather than acting independently of one another, these systems act in an integrated fashion to regulate cardiac gene expression in a coordinated manner. In fact, several cardiac-expressed miRNAs were found to be involved in the TBX5 [114, 121], GATA-4 [122-126], SRF/MYOCD [124, 126, 127], and PITX2 [97] regulatory network in settings of cardiovascular disease. There is evidence that circulating miRNAs may be used as biomarkers for patients with HFpEF, but their expression has not yet been assessed in the diastolic heart [128]. Nonetheless, each advance discussed above highlights the importance of multiple layers of molecular control in regulating cardiac gene expression at HFpEF.

Acknowledgments

This work was supported in part by funds from the Institute of Health Sciences and by a grant (GRC 2013/061) from the Autonomic Government of Galicia, Spain.

\section{Compliance with ethical standards}

The manuscript does not contain clinical studies or patient data.

\section{Conflict of interest}

The authors have declared that no competing interests exist. 


\section{References}

1. Loffredo FS, Nikolova AP, Pancoast JR, Lee RT (2014) Heart failure with preserved ejection fraction: molecular pathways of the aging myocardium. Circ Res 115:97-107. doi:10.1161/CIRCRESAHA.115.302929

2. Sharma K, Kass DA (2014) Heart failure with preserved ejection fraction: mechanisms, clinical features, and therapies. Circ Res 115:79-96. doi:10.1161/CIRCRESAHA.115.302922

3. Senni M, Paulus WJ, Gavazzi A, Fraser AG, Diez J, Solomon SD, Smiseth OA, Guazzi M, Lam CS, Maggioni AP et al (2014) New strategies for heart failure with preserved ejection fraction: the importance of targeted therapies for heart failure phenotypes. Eur Heart J 35:2797-2815. doi:10.1093/eurheartj/ehu204

4. Abbate A, Arena R, Abouzaki N, Van Tassell BW, Canada J, Shah K, Biondi-Zoccai G, Voelkel NF (2015) Heart failure with preserved ejection fraction: refocusing on diastole. Int J Cardiol 179:430-440. doi:10.1016/j.ijcard.2014.11.106

5. Ferrari R, Bohm M, Cleland JG, Paulus WJ, Pieske B, Rapezzi C, Tavazzi L (2015) Heart failure with preserved ejection fraction: uncertainties and dilemmas. Eur J Heart Fail 17:665-671. doi:10.1002/ejhf.304

6. Oktay AA, Shah SJ (2015) Diagnosis and management of heart failure with preserved ejection fraction: 10 key lessons. Curr Cardiol Rev 11:42-52. doi:10.2174/1573403X09666131117131217

7. Rodrigues PG, Leite-Moreira AF, Falcao-Pires I (2016) Myocardial reverse remodeling: how far can we rewind? Am J Physiol Heart Circ Physiol. doi:10.1152/ajpheart.00696.2015

8. Gomes AC, Falcao-Pires I, Pires AL, Bras-Silva C, Leite-Moreira AF (2013) Rodent models of heart failure: an updated review. Heart Fail Rev 18:219-249. doi:10.1007/s10741-012-9305-3

9. Horgan S, Watson C, Glezeva N, Baugh J (2014) Murine models of diastolic dysfunction and heart failure with preserved ejection fraction. J Card Fail 20:984-995. doi:10.1016/j.cardfail.2014.09.001

10. Connelly KA, Kelly DJ, Zhang Y, Prior DL, Martin J, Cox AJ, Thai K, Feneley MP, Tsoporis J, White KE et al (2007) Functional, structural and molecular aspects of diastolic heart failure in the diabetic (mRen-2)27 rat. Cardiovasc Res 76:280-291. doi:10.1016/j.cardiores.2007.06.022

11. Hamdani N, Bishu KG, von Frieling-Salewsky M, Redfield MM, Linke WA (2013) Deranged myofilament phosphorylation and function in experimental heart failure with preserved ejection fraction. Cardiovasc Res 97:464-471. doi:10.1093/cvr/cvs353

12. Tong CW, Nair NA, Doersch KM, Liu Y, Rosas PC (2014) Cardiac myosin-binding protein-C is a critical mediator of diastolic function. Pflugers Arch 466:451-457. doi:10.1007/s00424-014-1442-1

13. Sheng JJ, Feng HZ, Pinto JR, Wei H, Jin JP (2015) Increases of desmin and alpha-actinin in mouse cardiac myofibrils as a response to diastolic dysfunction. J Mol Cell Cardiol. doi:10.1016/j.yjmcc.2015.1010.1035

14. Rysa J, Leskinen H, Ilves M, Ruskoaho H (2005) Distinct upregulation of extracellular matrix genes in transition from hypertrophy to hypertensive heart failure. Hypertension 45:927-933. doi:10.1161/01.HYP.0000161873.27088.4c

15. Phrommintikul A, Tran L, Kompa A, Wang B, Adrahtas A, Cantwell D, Kelly DJ, Krum H (2008) Effects of a Rho kinase inhibitor on pressure overload induced cardiac hypertrophy and associated diastolic dysfunction. Am J Physiol Heart Circ Physiol 294:H1804-H1814. doi:10.1152/ajpheart.01078.2007

16. Regan JA, Mauro AG, Carbone S, Marchetti C, Gill R, Mezzaroma E, Valle Raleigh J, Salloum FN, Van Tassell BW, Abbate A et al (2015) A mouse model of heart failure with preserved ejection fraction due to chronic infusion of a low subpressor dose of angiotensin II. Am J Physiol Heart Circ Physiol 309:H771H778. doi:10.1152/ajpheart.00282.2015

17. Franssen C, Gonzalez Miqueo A (2016) The role of titin and extracellular matrix remodelling in heart failure with preserved ejection fraction. Neth Heart J 24:259-267. doi:10.1007/s12471-016-0812-Z

18. Ingle KA, Kain V, Goel M, Prabhu SD, Young ME, Halade GV (2015) Cardiomyocyte-specific Bmal1 deletion in mice triggers diastolic dysfunction, extracellular matrix response, and impaired resolution of inflammation. Am J Physiol Heart Circ Physiol 309:H1827-H1836. doi:10.1152/ajpheart.00608.2015

19. Jia G, Habibi J, DeMarco VG, Martinez-Lemus LA, Ma L, Whaley-Connell AT, Aroor AR, Domeier TL, Zhu Y, Meininger GA et al (2015) Endothelial mineralocorticoid receptor deletion prevents diet-induced cardiac diastolic dysfunction in females. Hypertension 66:1159-1167. doi:10.1161/HYPERTENSIONAHA.115.06015

20. Kathiriya IS, Nora EP, Bruneau BG (2015) Investigating the transcriptional control of cardiovascular development. Circ Res 116:700-714. doi:10.1161/CIRCRESAHA.116.302832

21. Nimura K, Kaneda Y (2015) Elucidating the mechanisms of transcription regulation during heart development by next-generation sequencing. J Hum Genet. doi:10.1038/jhg.2015.1084

22. Kohli S, Ahuja S, Rani V (2011) Transcription factors in heart: promising therapeutic targets in cardiac hypertrophy. Curr Cardiol Rev 7:262-271. doi:10.2174/157340311799960618

23. Mikhailov AT, Torrado M (2012) In search of novel targets for heart disease: myocardin and myocardinrelated transcriptional cofactors. Biochem Res Int 2012:973723. doi:10.1155/2012/973723 
24. Dirkx E, da Costa Martins PA, De Windt LJ (2013) Regulation of fetal gene expression in heart failure. Biochim Biophys Acta 1832:2414-2424. doi:10.1016/j.bbadis.2013.07.023

25. Fontaine F, Overman J, Francois M (2015) Pharmacological manipulation of transcription factor proteinprotein interactions: opportunities and obstacles. Cell Regen (Lond) 4:2. doi:10.1186/s13619-015-0015-x

26. Packham EA, Brook JD (2003) T-box genes in human disorders. Hum Mol Genet 12(Spec No 1):R37R44. doi: $10.1093 / \mathrm{hmg} / \mathrm{ddg} 077$

27. Plageman TF Jr, Yutzey KE (2005) T-box genes and heart development: putting the "T" in heart. Dev Dyn 232:11-20. doi:10.1002/dvdy.20201

28. Papaioannou VE (2014) The T-box gene family: emerging roles in development, stem cells and cancer. Development 141:3819-3833. doi:10.1242/dev.104471

29. Hatcher CJ, Goldstein MM, Mah CS, Delia CS, Basson CT (2000) Identification and localization of TBX5 transcription factor during human cardiac morphogenesis. Dev Dyn 219:90-95. doi:10.1002/10970177(200009)219:1<90:AID-DVDY1033>3.0.CO;2-L

30. Mori AD, Zhu Y, Vahora I, Nieman B, Koshiba-Takeuchi K, Davidson L, Pizard A, Seidman JG, Seidman CE, Chen XJ et al (2006) Tbx5-dependent rheostatic control of cardiac gene expression and morphogenesis. Dev Biol 297:566-586. doi:10.1016/j.ydbio.2006.05.023

31. Arnolds DE, Liu F, Fahrenbach JP, Kim GH, Schillinger KJ, Smemo S, McNally EM, Nobrega MA, Patel VV, Moskowitz IP (2012) TBX5 drives Scn5a expression to regulate cardiac conduction system function. J Clin Invest 122:2509-2518. doi:10.1172/JCI62617

32. Georges R, Nemer G, Morin M, Lefebvre C, Nemer M (2008) Distinct expression and function of alternatively spliced Tbx5 isoforms in cell growth and differentiation. Mol Cell Biol 28:4052-4067. doi:10.1128/MCB.02100-07

33. Yamak A, Georges RO, Sheikh-Hassani M, Morin M, Komati H, Nemer M (2015) Novel exons in the tbx5 gene locus generate protein isoforms with distinct expression domains and function. J Biol Chem 290:6844-6856. doi:10.1074/jbc.M114.634451

34. Liberatore CM, Searcy-Schrick RD, Yutzey KE (2000) Ventricular expression of tbx5 inhibits normal heart chamber development. Dev Biol 223:169-180. doi:10.1006/dbio.2000.9748

35. Patel C, Silcock L, McMullan D, Brueton L, Cox H (2012) TBX5 intragenic duplication: a family with an atypical Holt-Oram syndrome phenotype. Eur J Hum Genet 20:863-869. doi:10.1038/ejhg.2012.16

36. Bruneau BG, Nemer G, Schmitt JP, Charron F, Robitaille L, Caron S, Conner DA, Gessler M, Nemer M, Seidman CE et al (2001) A murine model of Holt-Oram syndrome defines roles of the T-box transcription factor Tbx5 in cardiogenesis and disease. Cell 106:709-721. doi:10.1016/S00928674(01)00493-7

37. Al-Qattan MM, Abou Al-Shaar H (2015) Molecular basis of the clinical features of Holt-Oram syndrome resulting from missense and extended protein mutations of the TBX5 gene as well as TBX5 intragenic duplications. Gene 560:129-136. doi:10.1016/j.gene.2015.02.017

38. Zhu Y, Gramolini AO, Walsh MA, Zhou YQ, Slorach C, Friedberg MK, Takeuchi JK, Sun H, Henkelman RM, Backx PH et al (2008) Tbx5-dependent pathway regulating diastolic function in congenital heart disease. Proc Natl Acad Sci USA 105:5519-5524. doi:10.1073/pnas.0801779105

39. Antonini-Canterin F, Carerj S, Di Bello V, Di Salvo G, La Carrubba S, Vriz O, Pavan D, Balbarini A, Nicolosi GL (2009) Arterial stiffness and ventricular stiffness: a couple of diseases or a coupling disease? A review from the cardiologist's point of view. Eur J Echocardiogr 10:36-43. doi:10.1093/ejechocard/jen236

40. Levy D, Ehret GB, Rice K, Verwoert GC, Launer LJ, Dehghan A, Glazer NL, Morrison AC, Johnson AD, Aspelund T et al (2009) Genome-wide association study of blood pressure and hypertension. Nat Genet 41:677-687. doi:10.1038/ng.384

41. Zhou YQ, Zhu Y, Bishop J, Davidson L, Henkelman RM, Bruneau BG, Foster FS (2005) Abnormal cardiac inflow patterns during postnatal development in a mouse model of Holt-Oram syndrome. Am J Physiol Heart Circ Physiol 289:H992-H1001. doi:10.1152/ajpheart.00027.2005

42. Pikkarainen S, Tokola H, Kerkela R, Ruskoaho H (2004) GATA transcription factors in the developing and adult heart. Cardiovasc Res 63:196-207. doi:10.1016/j.cardiores.2004.03.025

43. Peterkin T, Gibson A, Loose M, Patient R (2005) The roles of GATA-4, -5 and -6 in vertebrate heart development. Semin Cell Dev Biol 16:83-94. doi:10.1016/j.semcdb.2004.10.003

44. Rysa J, Tenhunen O, Serpi R, Soini Y, Nemer M, Leskinen H, Ruskoaho H (2010) GATA-4 is an angiogenic survival factor of the infarcted heart. Circ Heart Fail 3:440-450. doi:10.1161/CIRCHEARTFAILURE.109.889642

45. Lepore JJ, Cappola TP, Mericko PA, Morrisey EE, Parmacek MS (2005) GATA-6 regulates genes promoting synthetic functions in vascular smooth muscle cells. Arterioscler Thromb Vasc Biol 25:309_ 314. doi:10.1161/01.ATV.0000152725.76020.3c

46. Zhao R, Watt AJ, Battle MA, Li J, Bondow BJ, Duncan SA (2008) Loss of both GATA4 and GATA6 blocks cardiac myocyte differentiation and results in acardia in mice. Dev Biol 317:614-619. doi:10.1016/j.ydbio.2008.03.013 
47. Liang Q, De Windt LJ, Witt SA, Kimball TR, Markham BE, Molkentin JD (2001) The transcription factors GATA4 and GATA6 regulate cardiomyocyte hypertrophy in vitro and in vivo. J Biol Chem 276:30245-30253. doi:10.1074/jbc.M102174200

48. van Berlo JH, Aronow BJ, Molkentin JD (2013) Parsing the roles of the transcription factors GATA-4 and GATA-6 in the adult cardiac hypertrophic response. PLoS ONE 8:e84591. doi:10.1371/journal.pone.0084591

49. van Berlo JH, Elrod JW, van den Hoogenhof MM, York AJ, Aronow BJ, Duncan SA, Molkentin JD (2010) The transcription factor GATA-6 regulates pathological cardiac hypertrophy. Circ Res 107:10321040. doi:10.1161/CIRCRESAHA.110.220764

50. Oka T, Maillet M, Watt AJ, Schwartz RJ, Aronow BJ, Duncan SA, Molkentin JD (2006) Cardiac-specific deletion of Gata4 reveals its requirement for hypertrophy, compensation, and myocyte viability. Circ Res 98:837-845. doi:10.1161/01.RES.0000215985.18538.c4

51. Prendiville TW, Guo H, Lin Z, Zhou P, Stevens SM, He A, VanDusen N, Chen J, Zhong L, Wang DZ et al (2015) Novel roles of GATA4/6 in the postnatal heart identified through temporally controlled, cardiomyocyte-specific gene inactivation by adeno-associated virus delivery of Cre recombinase. PLoS ONE 10:e128105. doi:10.1371/journal.pone.0128105

52. Ishiwata T, Nakazawa M, Pu WT, Tevosian SG, Izumo S (2003) Developmental changes in ventricular diastolic function correlate with changes in ventricular myoarchitecture in normal mouse embryos. Circ Res 93:857-865. doi:10.1161/01.RES.0000100389.57520.1A

53. Pu WT, Ishiwata T, Juraszek AL, Ma Q, Izumo S (2004) GATA4 is a dosage-sensitive regulator of cardiac morphogenesis. Dev Biol 275:235-244. doi:10.1016/j.ydbio.2004.08.008

54. Charron F, Paradis P, Bronchain O, Nemer G, Nemer M (1999) Cooperative interaction between GATA-4 and GATA-6 regulates myocardial gene expression. Mol Cell Biol 19:4355-4365

55. McCulley DJ, Black BL (2012) Transcription factor pathways and congenital heart disease. Curr Top Dev Biol 100:253-277. doi:10.1016/B978-0-12-387786-4.00008-7

56. Zhou B, Ma Q, Kong SW, Hu Y, Campbell PH, McGowan FX, Ackerman KG, Wu B, Tevosian SG, Pu WT (2009) Fog2 is critical for cardiac function and maintenance of coronary vasculature in the adult mouse heart. J Clin Invest 119:1462-1476. doi:10.1172/JCI38723

57. Rouf R, Greytak S, Wooten EC, Wu J, Boltax J, Picard M, Svensson EC, Dillmann WH, Patten RD, Huggins GS (2008) Increased FOG-2 in failing myocardium disrupts thyroid hormone-dependent SERCA2 gene transcription. Circ Res 103:493-501. doi:10.1161/CIRCRESAHA.108.181487

58. Miano JM (2003) Serum response factor: toggling between disparate programs of gene expression. J Mol Cell Cardiol 35:577-593. doi:10.1016/S0022-2828(03)00110-X

59. Miano JM, Long X, Fujiwara K (2007) Serum response factor: master regulator of the actin cytoskeleton and contractile apparatus. Am J Physiol Cell Physiol 292:C70-C81. doi:10.1152/ajpcell.00386.2006

60. Zhang X, Azhar G, Helms S, Burton B, Huang C, Zhong Y, Gu X, Fang H, Tong W, Wei JY (2011) Identification of new SRF binding sites in genes modulated by SRF over-expression in mouse hearts. Gene Regul Syst Biol 5:41-59. doi:10.4137/GRSB.S7457

61. Miano JM (2010) Role of serum response factor in the pathogenesis of disease. Lab Invest 90:1274-1284. doi:10.1038/labinvest.2010.104

62. Mikhailov AT, Torrado M (2010) NKX2.5 and SRF in postnatal cardiac remodeling: is there a link? In: Mikhailov AT, Torrado M (eds) Shaping the heart in development and disease. Transworld Research Network, Trivandrum, pp 145-164

63. Zhang X, Azhar G, Furr MC, Zhong Y, Wei JY (2003) Model of functional cardiac aging: young adult mice with mild overexpression of serum response factor. Am J Physiol Regul Integr Comp Physiol 285:R552-R560. doi:10.1152/ajpregu.00631.2002

64. Angelini A, Li Z, Mericskay M, Decaux JF (2015) Regulation of connective tissue growth factor and cardiac fibrosis by an SRF/microRNA-133a Axis. PLoS ONE 10:e0139858. doi:10.1371/journal.pone.0139858

65. Cen B, Selvaraj A, Prywes R (2004) Myocardin/MKL family of SRF coactivators: key regulators of immediate early and muscle specific gene expression. J Cell Biochem 93:74-82. doi:10.1002/jcb.20199

66. Pipes GC, Creemers EE, Olson EN (2006) The myocardin family of transcriptional coactivators: versatile regulators of cell growth, migration, and myogenesis. Genes Dev 20:1545-1556. doi:10.1101/gad.1428006

67. Parmacek MS (2007) Myocardin-related transcription factors: critical coactivators regulating cardiovascular development and adaptation. Circ Res 100:633-644. doi:10.1161/01.RES.0000259563.61091.e8

68. Miano JM (2015) Myocardin in biology and disease. J Biomed Res 29:3-19. doi:10.7555/JBR.29.20140151

69. Huang J, Min L, Cheng L, Yuan LJ, Zhu X, Stout AL, Chen M, Li J, Parmacek MS (2009) Myocardin is required for cardiomyocyte survival and maintenance of heart function. Proc Natl Acad Sci USA 106:18734-18739. doi:10.1073/pnas.0910749106 
70. Torrado M, Centeno C, López E, Mikhailov AT (2009) In-vivo forced expression of myocardin in ventricular myocardium transiently impairs systolic performance in early neonatal pig heart. Int J Dev Biol 53:1457-1467. doi:10.1387/ijdb.072366mt

71. Kumar A, Crawford K, Close L, Madison M, Lorenz J, Doetschman T, Pawlowski S, Duffy J, Neumann J, Robbins J et al (1997) Rescue of cardiac alpha-actin-deficient mice by enteric smooth muscle gammaactin. Proc Natl Acad Sci USA 94:4406-4411

72. Torrado M, Iglesias R, Centeno A, Lopez E, Mikhailov AT (2011) Targeted gene-silencing reveals the functional significance of myocardin signaling in the failing heart. PLoS ONE 6:e26392. doi:10.1371/journal.pone.0026392

73. Chorley BN, Campbell MR, Wang X, Karaca M, Sambandan D, Bangura F, Xue P, Pi J, Kleeberger SR, Bell DA (2012) Identification of novel NRF2-regulated genes by ChIP-Seq: influence on retinoid X receptor alpha. Nucleic Acids Res 40:7416-7429. doi:10.1093/nar/gks409

74. Jaiswal AK (2004) Nrf2 signaling in coordinated activation of antioxidant gene expression. Free Radic Biol Med 36:1199-1207. doi:10.1016/j.freeradbiomed.2004.02.074

75. Niture SK, Kaspar JW, Shen J, Jaiswal AK (2010) Nrf2 signaling and cell survival. Toxicol Appl Pharmacol 244:37-42. doi:10.1016/j.taap.2009.06.009

76. Li J, Ichikawa T, Janicki JS, Cui T (2009) Targeting the Nrf2 pathway against cardiovascular disease. Expert Opin Ther Targets 13:785-794. doi:10.1517/14728220903025762

77. Zhou S, Sun W, Zhang Z, Zheng Y (2014) The role of Nrf2-mediated pathway in cardiac remodeling and heart failure. Oxid Med Cell Longev 2014:260429. doi:10.1155/2014/260429

78. Cho HY, Marzec J, Kleeberger SR (2015) Functional polymorphisms in Nrf2: implications for human disease. Free Radic Biol Med 88:362-372. doi:10.1016/j.freeradbiomed.2015.06.012

79. Chan K, Lu R, Chang JC, Kan YW (1996) NRF2, a member of the NFE2 family of transcription factors, is not essential for murine erythropoiesis, growth, and development. Proc Natl Acad Sci USA 93:1394313948

80. Li J, Ichikawa T, Villacorta L, Janicki JS, Brower GL, Yamamoto M, Cui T (2009) Nrf2 protects against maladaptive cardiac responses to hemodynamic stress. Arterioscler Thromb Vasc Biol 29:1843-1850. doi:10.1161/ATVBAHA.109.189480

81. Xu B, Zhang J, Strom J, Lee S, Chen QM (2014) Myocardial ischemic reperfusion induces de novo Nrf2 protein translation. Biochim Biophys Acta 1842:1638-1647. doi:10.1016/j.bbadis.2014.06.002

82. Tao G, Kahr PC, Morikawa Y, Zhang M, Rahmani M, Heallen TR, Li L, Sun Z, Olson EN, Amendt BA et al (2016) Pitx2 promotes heart repair by activating the antioxidant response after cardiac injury. Nature. doi:10.1038/nature17959

83. Erkens R, Kramer CM, Luckstadt W, Panknin C, Krause L, Weidenbach M, Dirzka J, Krenz T, Mergia E, Suvorava $\mathrm{T}$ et al (2015) Left ventricular diastolic dysfunction in Nrf2 knock out mice is associated with cardiac hypertrophy, decreased expression of SERCA2a, and preserved endothelial function. Free Radic Biol Med 89:906-917. doi:10.1016/j.freeradbiomed.2015.10.409

84. Howden R (2013) Nrf2 and cardiovascular defense. Oxid Med Cell Longev 2013:104308 doi: $10.1155 / 2013 / 104308$

85. Cominacini L, Mozzini C, Garbin U, Pasini A, Stranieri C, Solani E, Vallerio P, Tinelli IA, Fratta Pasini A (2015) Endoplasmic reticulum stress and Nrf2 signaling in cardiovascular diseases. Free Radic Biol Med 88:233-242. doi:10.1016/j.freeradbiomed.2015.05.027

86. Seymour EM, Bennink MR, Bolling SF (2013) Diet-relevant phytochemical intake affects the cardiac $\mathrm{AhR}$ and nrf2 transcriptome and reduces heart failure in hypertensive rats. J Nutr Biochem 24:1580 1586. doi:10.1016/j.jnutbio.2013.01.008

87. From AM, Scott CG, Chen HH (2010) The development of heart failure in patients with diabetes mellitus and pre-clinical diastolic dysfunction a population-based study. J Am Coll Cardiol 55:300-305. doi:10.1016/j.jacc.2009.12.003

88. Liu Q, Wang S, Cai L (2014) Diabetic cardiomyopathy and its mechanisms: role of oxidative stress and damage. J Diabetes Investig 5:623-634. doi:10.1111/jdi.12250

89. Chen J, Zhang Z, Cai L (2014) Diabetic cardiomyopathy and its prevention by nrf2: current status. Diabetes Metab J 38:337-345. doi:10.4093/dmj.2014.38.5.337

90. Semina EV, Reiter R, Leysens NJ, Alward WL, Small KW, Datson NA, Siegel-Bartelt J, Bierke-Nelson D, Bitoun P, Zabel BU et al (1996) Cloning and characterization of a novel bicoid-related homeobox transcription factor gene, RIEG, involved in Rieger syndrome. Nat Genet 14:392-399. doi:10.1038/ng1296-392

91 Hjalt TA, Semina EV (2005) Current molecular understanding of Axenfeld-Rieger syndrome. Expert Rev Mol Med 7:1-17. doi:10.1017/S1462399405010082

92. Zhao CM, Peng LY, Li L, Liu XY, Wang J, Zhang XL, Yuan F, Li RG, Qiu XB, Yang YQ (2015) PITX2 loss-of-function mutation contributes to congenital endocardial cushion defect and Axenfeld-Rieger syndrome. PLoS ONE 10:e0124409. doi:10.1371/journal.pone.0124409

93. Hjalt TA, Semina EV, Amendt BA, Murray JC (2000) The Pitx2 protein in mouse development. Dev Dyn 218:195-200. doi:10.1002/(SICI)1097-0177(200005)218:1<195:AID-DVDY17>3.0.CO;2-C 
94. Kirchhof P, Kahr PC, Kaese S, Piccini I, Vokshi I, Scheld HH, Rotering H, Fortmueller L, Laakmann S, Verheule $S$ et al (2011) PITX2c is expressed in the adult left atrium, and reducing Pitx $2 c$ expression promotes atrial fibrillation inducibility and complex changes in gene expression. Circ Cardiovasc Genet 4:123-133. doi:10.1161/CIRCGENETICS.110.958058

95. Kahr PC, Piccini I, Fabritz L, Greber B, Scholer H, Scheld HH, Hoffmeier A, Brown NA, Kirchhof P (2011) Systematic analysis of gene expression differences between left and right atria in different mouse strains and in human atrial tissue. PLoS ONE 6:e26389. doi:10.1371/journal.pone.0026389

96. Hsu J, Hanna P, Van Wagoner DR, Barnard J, Serre D, Chung MK, Smith JD (2012) Whole genome expression differences in human left and right atria ascertained by RNA sequencing. Circ Cardiovasc Genet 5:327-335. doi:10.1161/CIRCGENETICS.111.961631

97. Torrado M, Franco D, Hernandez-Torres F, Crespo-Leiro MG, Iglesias-Gil C, Castro-Beiras A, Mikhailov AT (2014) Pitx2c is reactivated in the failing myocardium and stimulates myf5 expression in cultured cardiomyocytes. PLoS ONE 9:e90561. doi:10.1371/journal.pone.0090561

98 Hernandez-Torres F, Franco D, Aranega AE, Navarro F (2015) Expression patterns and immunohistochemical localization of PITX2B transcription factor in the developing mouse heart. Int J Dev Biol 59:247-254. doi:10.1387/ijdb.140224fh

99. Cox CJ, Espinoza HM, McWilliams B, Chappell K, Morton L, Hjalt TA, Semina EV, Amendt BA (2002) Differential regulation of gene expression by PITX2 isoforms. J Biol Chem 277:25001-25010. doi:10.1074/jbc.M201737200

100. Kioussi C, Briata P, Baek SH, Rose DW, Hamblet NS, Herman T, Ohgi KA, Lin C, Gleiberman A, Wang J et al (2002) Identification of a Wnt/Dvl/beta-Catenin - > Pitx2 pathway mediating cell-typespecific proliferation during development. Cell 111:673-685. doi:10.1016/S0092-8674(02)01084-X

101. Venugopalan SR, Amen MA, Wang J, Wong L, Cavender AC, D’Souza RN, Akerlund M, Brody SL, Hjalt TA, Amendt BA (2008) Novel expression and transcriptional regulation of FoxJ1 during oro-facial morphogenesis. Hum Mol Genet 17:3643-3654. doi:10.1093/hmg/ddn258

102. Vadlamudi U, Espinoza HM, Ganga M, Martin DM, Liu X, Engelhardt JF, Amendt BA (2005) PITX2, beta-catenin and LEF-1 interact to synergistically regulate the LEF-1 promoter. J Cell Sci 118:11291137. doi: $10.1242 /$ jcs. 01706

103. Ganga M, Espinoza HM, Cox CJ, Morton L, Hjalt TA, Lee Y, Amendt BA (2003) PITX2 isoformspecific regulation of atrial natriuretic factor expression: synergism and repression with $\mathrm{Nkx} 2.5$. J Biol Chem 278:22437-22445. doi:10.1074/jbc.M210163200

104. Toro R, Saadi I, Kuburas A, Nemer M, Russo AF (2004) Cell-specific activation of the atrial natriuretic factor promoter by PITX2 and MEF2A. J Biol Chem 279:52087-52094. doi:10.1074/jbc.M404802200

105. Zacharias AL, Lewandoski M, Rudnicki MA, Gage PJ (2011) Pitx2 is an upstream activator of extraocular myogenesis and survival. Dev Biol 349:395-405. doi:10.1016/j.ydbio.2010.10.028

106. Zhou M, Liao Y, Tu X (2015) The role of transcription factors in atrial fibrillation. J Thorac Dis 7:152158. doi:10.3978/j.issn.2072-1439.2015.01.21

107. Tessari A, Pietrobon M, Notte A, Cifelli G, Gage PJ, Schneider MD, Lembo G, Campione M (2008) Myocardial Pitx2 differentially regulates the left atrial identity and ventricular asymmetric remodeling programs. Circ Res 102:813-822. doi:10.1161/CIRCRESAHA.107.163188

108. Tao Y, Zhang M, Li L, Bai Y, Zhou Y, Moon AM, Kaminski HJ, Martin JF (2014) Pitx2, an atrial fibrillation predisposition gene, directly regulates ion transport and intercalated disc genes. Circ Cardiovasc Genet 7:23-32. doi:10.1161/CIRCGENETICS.113.000259

109. Chinchilla A, Daimi H, Lozano-Velasco E, Dominguez JN, Caballero R, Delpon E, Tamargo J, Cinca J, Hove-Madsen L, Aranega AE et al (2011) PITX2 insufficiency leads to atrial electrical and structural remodeling linked to arrhythmogenesis. Circ Cardiovasc Genet 4:269-279. doi:10.1161/CIRCGENETICS.110.958116

110. Franco D, Chinchilla A, Aranega AE (2012) Transgenic insights linking pitx2 and atrial arrhythmias. Front Physiol 3:206. doi:10.3389/fphys.2012.00206

111. Franco D, Chinchilla A, Daimi H, Dominguez JN, Aranega A (2011) Modulation of conductive elements by Pitx2 and their impact on atrial arrhythmogenesis. Cardiovasc Res 91:223-231. doi:10.1093/cvr/cvr078

112. Franco D, Christoffels VM, Campione M (2014) Homeobox transcription factor Pitx2: the rise of an asymmetry gene in cardiogenesis and arrhythmogenesis. Trends Cardiovasc Med 24:23-31. doi:10.1016/j.tcm.2013.06.001

113. Huang Y, Wang C, Yao Y, Zuo X, Chen S, Xu C, Zhang H, Lu Q, Chang L, Wang F et al (2015) Molecular basis of gene-gene interaction: cyclic cross-regulation of gene expression and post-GWAS gene-gene interaction involved in atrial fibrillation. PLoS Genet 11:e1005393. doi:10.1371/journal.pgen.1005393

114. Torrado M, Franco D, Lozano-Velasco E, Hernandez-Torres F, Calvino R, Aldama G, Centeno A, Castro-Beiras A, Mikhailov A (2015) A microRNA-transcription factor blueprint for early atrial arrhythmogenic remodeling. Biomed Res Int 2015:263151. doi:10.1155/2015/263151 
115. Santerre RF, Bales KR, Janney MJ, Hannon K, Fisher LF, Bailey CS, Morris J, Ivarie R, Smith CK 2nd (1993) Expression of bovine myf5 induces ectopic skeletal muscle formation in transgenic mice. Mol Cell Biol 13:6044-6051

116. Edwards JG, Lyons GE, Micales BK, Malhotra A, Factor S, Leinwand LA (1996) Cardiomyopathy in transgenic myf5 mice. Circ Res 78:379-387. doi:10.1161/01.RES.78.3.379

117. Sun N, Yazawa M, Liu J, Han L, Sanchez-Freire V, Abilez OJ, Navarrete EG, Hu S, Wang L, Lee A et al (2012) Patient-specific induced pluripotent stem cells as a model for familial dilated cardiomyopathy. Sci Transl Med 4:130ra147. doi:10.1126/scitranslmed.3003552

118. Su D, Jing S, Guan L, Li Q, Zhang H, Gao X, Ma X (2014) Role of Nodal-PITX2C signaling pathway in glucose-induced cardiomyocyte hypertrophy. Biochem Cell Biol 92:183-190. doi:10.1139/bcb-20130124

119. Scimia MC, Sydnes KE, Zuppo DA, Koch WJ (2014) Methods to improve cardiac gene therapy expression. Expert Rev Cardiovasc Ther 12:1317-1326. doi:10.1586/14779072.2014.967683

120. Nair N, Gupta S, Collier IX, Gongora E, Vijayaraghavan K (2014) Can microRNAs emerge as biomarkers in distinguishing HFpEF versus HFrEF? Int J Cardiol 175:395-399. doi:10.1016/j.ijcard.2014.06.027

121. Wang F, Yang XY, Zhao JY, Yu LW, Zhang P, Duan WY, Chong M, Gui YH (2014) miR-10a and miR-10b target the 3'-untranslated region of TBX5 to repress its expression. Pediatr Cardiol 35:10721079. doi:10.1007/s00246-014-0901-y

122. Callis TE, Pandya K, Seok HY, Tang RH, Tatsuguchi M, Huang ZP, Chen JF, Deng Z, Gunn B, Shumate J et al (2009) MicroRNA-208a is a regulator of cardiac hypertrophy and conduction in mice. J Clin Invest 119:2772-2786. doi:10.1172/JCI36154

123. Han M, Yang Z, Sayed D, He M, Gao S, Lin L, Yoon S, Abdellatif M (2012) GATA4 expression is primarily regulated via a miR-26b-dependent post-transcriptional mechanism during cardiac hypertrophy. Cardiovasc Res 93:645-654. doi:10.1093/cvr/cvs001

124. Liu N, Bezprozvannaya S, Williams AH, Qi X, Richardson JA, Bassel-Duby R, Olson EN (2008) MicroRNA-133a regulates cardiomyocyte proliferation and suppresses smooth muscle gene expression in the heart. Genes Dev 22:3242-3254. doi:10.1101/gad.1738708

125. Wang DZ (2010) MicroRNAs in cardiac development and remodeling. Pediatr Cardiol 31:357-362. doi:10.1007/s00246-010-9641-9

126. Liao XH, Wang N, Zhao DW, Zheng DL, Zheng L, Xing WJ, Zhou H, Cao DS, Zhang TC (2014) NFkappaB (p65) negatively regulates myocardin-induced cardiomyocyte hypertrophy through multiple mechanisms. Cell Signal 26:2738-2748. doi:10.1016/j.cellsig.2014.08.006

127. Wang K, Long B, Zhou J, Li PF (2010) MiR-9 and NFATc3 regulate myocardin in cardiac hypertrophy. J Biol Chem 285:11903-11912. doi:10.1074/jbc.M109.098004

128. Nair N, Kumar S, Gongora E, Gupta S (2013) Circulating miRNA as novel markers for diastolic dysfunction. Mol Cell Biochem 376:33-40. doi:10.1007/s11010-012-1546-x

129. Marchler-Bauer A, Derbyshire MK, Gonzales NR, Lu S, Chitsaz F, Geer LY, Geer RC, He J, Gwadz M, Hurwitz DI et al (2015) CDD: NCBI's conserved domain database. Nucleic Acids Res 43:D222-D226. doi:10.1093/nar/gku1221

130. Garg V, Kathiriya IS, Barnes R, Schluterman MK, King IN, Butler CA, Rothrock CR, Eapen RS, Hirayama-Yamada K, Joo K et al (2003) GATA4 mutations cause human congenital heart defects and reveal an interaction with TBX5. Nature 424:443-447. doi:10.1038/nature01827

131. Kodo K, Nishizawa T, Furutani M, Arai S, Ishihara K, Oda M, Makino S, Fukuda K, Takahashi T, Matsuoka R et al (2012) Genetic analysis of essential cardiac transcription factors in 256 patients with non-syndromic congenital heart defects. Circ J 76:1703-1711. doi:10.1253/circj.CJ-11-1389

132. Wang C, Cao D, Wang Q, Wang DZ (2011) Synergistic activation of cardiac genes by myocardin and Tbx5. PLoS ONE 6:e24242. doi:10.1371/journal.pone.0024242

133. Shang Y, Yoshida T, Amendt BA, Martin JF, Owens GK (2008) Pitx2 is functionally important in the early stages of vascular smooth muscle cell differentiation. J Cell Biol 181:461-473. doi:10.1083/jcb.200711145

134. Martin DM, Amendt BA, Brown NA (2010) Pitx2 in cardiac left-right asymmetry and human disease. In: Rosenthal N, Harvey RP (eds) Heart development and regeneration, vol 1. Academic Press, New York, pp 307-320

135. Diedrichs H, Chi M, Boelck B, Mehlhorn U, Schwinger RH (2004) Increased regulatory activity of the calcineurin/NFAT pathway in human heart failure. Eur J Heart Fail 6:3-9. doi:10.1016/j.ejheart.2003.07.007

136. Chang J, Wei L, Otani T, Youker KA, Entman ML, Schwartz RJ (2003) Inhibitory cardiac transcription factor, SRF-N, is generated by caspase 3 cleavage in human heart failure and attenuated by ventricular unloading. Circulation 108:407-413. doi:10.1161/01.CIR.0000084502.02147.83

137. Torrado M, Lopez E, Centeno A, Medrano C, Castro-Beiras A, Mikhailov AT (2003) Myocardin mRNA is augmented in the failing myocardium: expression profiling in the porcine model and human dilated cardiomyopathy. J Mol Med 81:566-577 
138. Tan Y, Ichikawa T, Li J, Si Q, Yang H, Chen X, Goldblatt CS, Meyer CJ, Li X, Cai L et al (2011) Diabetic downregulation of Nrf2 activity via ERK contributes to oxidative stress-induced insulin resistance in cardiac cells in vitro and in vivo. Diabetes 60:625-633. doi:10.2337/db10-1164 